\title{
Neonatal performances in 3 lines of rabbit (litter sizes, litter and individual weights)
}

\author{
JS Vicente, F García-Ximénez, MP Viudes-de-Castro
}

\author{
Departamento de Ciencia Animal, Universidad Politécnica de Valencia, \\ Camino de Vera 14, Valencia 46022, Spain
}

(Received 15 June 1994; accepted 17 October 1994)

\begin{abstract}
Summary - The linear and curve-linear relationship between the total number of born young rabbits and the following traits were studied: number of born live, litter or individual weights of born live. Data from 260 births belonging to 3 selected rabbit strains were used. Of 3 lines studied, only line A (selected for litter size at weaning) showed curve-linear regression coefficient in the 3 studied traits, while line $V$ and $R$ showed curve-linear relationship for 2: litter and individual weight (selected for litter size at weaning and growth rate, respectively). For live young rabbits, the regression coefficients of line $A$ were $0.86 \pm 0.02$ and $-0.04 \pm 0.01(P<0.01)$, while line $V$ and $R$ showed a similar linear relationship (linear regression coefficient $0.96 \pm 0.05$ and $0.97 \pm 0.06$ ). Non differences among the lines were observed for the analysis of litter weight (linear: $37.7 \pm 2.4$ and curve-linear: $-1.23 \pm 0.54$ ). The evolution of individual weight when increasing the total number of young rabbits at birth showed a curvelinear relationship in the 3 lines. Line $A$ seemed to show a more evident curve-linear trend (linear: $-2.57 \pm 0.11$ and curve linear: $0.19 \pm 0.01, P<0.001$ ). The studied curve-linear relationship might indicate reproductive limitations to line $A$.
\end{abstract}

individual weight / litter weight / litter size / rabbits

Résumé - Performances à la naissance de 3 souches de lapin (taille de la portée, poids de la portée et poids individuel). L'étude de la relation entre la taille de la portée à la naissance et le nombre de lapereaux vivants, le poids de la portée et le poids individuel des lapereaux a été effectuée. Les données de 260 mise bas de 3 souches sélectionnées ont été analysées. On peut noter une relation uniquement linéaire entre le nombre total de lapereaux nés et le nombre de lapereaux nés vivants dans les 3 souches (coefficient linéaire: $0,94 \pm 0,03$ ). Cependant, des différences significatives entre souches ont été trouvées $(\mathrm{P}<0,001)$. Les coefficients de régression pour la souche $A$ étaient $0,86 \pm$ 0,02 et $-0,04 \pm 0,01(\mathrm{P}<0,01)$, tandis que les souches $V$ et $R$ montraient une évolution linéaire similaire (coefficients de régression linéaire : 0,96 $\pm 0,05$ et $0,97 \pm 0,06$ ). Pour le caractère poids de la portée, la relation a été non-linéaire (linéaire : $37,7 \pm 2,4$, non-linéaire : $-1,23 \pm 0,54$ ). Nous n'avons pas trouvé de différences entre souches pour le poids de la portée. Les relations entre le poids individuel de lapereaux et le nombre de lapereaux nés étaient non linéaires (linéaire : $-2,18 \pm 0,01$, non linéaire: $0,11 \pm 0,01)$. II semble que les souches $A$ et $V$ montrent un comportement plus nettement non-linéaire que la souche $R$.

poids individuel / poids de la portée / taille de la portée / lapin 


\section{INTRODUCTION}

In multiparous species, there is experimental evidence that in late gestation the foetuses do not normally grow to their maximum genetic potential (Gluckman, 1986), because the number of foetuses sharing the blood supply in the uterus affects the size and the weight of the individual young (Widdowson, 1976). The major limiting factor in the regulation of prenatal growth is the uterus, despite its remarkable distensibility and growth during pregnancy.

The higher the number of foetuses at birth, the greater the total weight of litter. However, the relationship between these traits does not appear to be linear (SalmonLegagneur, 1968; Wilmut et al, 1990), which implies a progressive reduction of individual weight of young at birth when the number of foetuses increases. Even for uniparous species such as cattle, when multiple births occur or are induced, the total weights of the calves increase from single to quadruplets (38 to 67 ), but the individual weights decrease (38 to 17; Holland and Odde, 1992).

In rabbits, Breuer and Claussen (1977) observed a negative correlation between the foetal weight and the litter size. Duncan (1969) observed in rabbits that the more foetuses there were in the uterine horn, the lower the maternal blood flow to the placenta, which was more likely to result in the appearance of runts. Adams (1962) proposed the existence of limits for the reduction in foetal and placental development rates of live young rabbits at birth. Moreover, in rabbits, as in other species, a negative relationship between the number of gestated foetuses and gestation length has been observed (Korda and Dembrowsky, 1968; Torres et al, 1986), which further lim- its the birth weight of each member of a multiple birth (Widdowson, 1976). If birth weight is less than the optimum weight, energy reserves and thermoregulatory capacity are reduced and perinatal mortality is increased.

The aim of this study was to detect the existence or not of limitations in the number of live young rabbits at birth, on the litter weight and on the individual weight at birth of 3 selected lines of rabbits.

\section{MATERIALS AND METHODS}

Three selected rabbit lines were used. Two of these, line A (White New Zealand) and line V (Synthetic breed), had been selected on litter size at weaning.The 3rd, line R (Synthetic breed), had been selected on growth rate from weaning to slaughter (28-70 d of age). The selection methodologies were described by Estany et al (1988).

A total of 2565 young rabbits from 260 births were used in this study ( 107 from line V, 75 from line $A$ and 78 from line $R$ ). Non primiparous does were used (2nd parturition: 91 litters; from 3rd to 9th parturition: 169 litters). During the $24 \mathrm{~h}$ following birth, nests were inspected and the live young were weighed. The weight of stillborn rabbits was not recorded because their weight was not a reliable estimate of their live weight at birth. At the time of nest inspection, the dead pups had already experienced both decomposition and dehydration.

The following measurements were recorded for each of the litters:

$a-$ Line $(A, V$ and $R$ );

$b$ - Total number of young at birth (stillborn and live);

c-Number of live young at birth;

$\mathrm{d}$-Individual weight of live young at birth (g);

e - Litter weight at birth (weight of live young) (g);

$f$ - Parity: 2 classes included 2 nd and subsequent (3rd to 9th) parturition records, respectively. 1991. 


\section{Statistical analysis}

An analysis was performed to evaluate the effects of line and parity on the total number of young rabbits at birth. The model used was:

$$
Y_{i j k}=\mu+L_{i}+P_{j}+e_{i j k}
$$

where $Y_{i j k}$ is total number of young rabbits at birth; $\mu$ is the population mean; $L_{i}$ is the line $(V, A, R)$; and $P_{j}$ is the parity (2nd, subsequent).

To examine linear or curve-linear relationship between the total number of young rabbits and the number of live young rabbits or litter weight, the following model was fitted:

$$
\begin{gathered}
Y_{i j k}=\mu+L_{i}+P_{j}+b\left(T Y R_{i j k}-\mu_{T Y R}\right) \\
+c\left(T Y R_{i j k}-\mu_{T Y R}\right) 2+e_{i j k}
\end{gathered}
$$

where $Y$ is live young rabbits (AYR) or litter weight $(L W) ; \mu$ is the population mean; $L_{i}$ is the line $(V, A$, $R$ ); $P_{j}$ is the parity (2nd, subsequent); $b$ and $c$ are linear and quadratic regression coefficients, respectively, of the dependent variable on the total number of young rabbits (TYR); and $e_{i j k}$ is the residual.

In preliminary analysis, the interaction line ${ }^{*}$ parity was included in the model. Interaction was not significant $(P>0.05)$. The Tuckey test was used to compare means.

When line factor was significant, a model was fitted for each line. The analyses were developed using PROC GLM in SAS (SAS Institute, 1989).

Relationships between the total number of young rabbits and the individual weight of the young were studied, including in the model the aleatory common litter effect $\left(Q_{k}\right)$ :

$$
\begin{gathered}
Y_{i j k l}=\mu+L_{i}+P_{j}+Q_{k}+b\left(T Y R_{i j k l}-\mu_{T Y R}\right) \\
+c\left(T Y R_{i j k l}-\mu_{T Y R}\right)^{2}+e_{i j k l}
\end{gathered}
$$

Analysis was performed with DFREML programs of Meyer (1988).

\section{RESULTS}

The maximum and minimum values of total young rabbits at birth were 19 and 3 in line $V, 15$ and 2 in line $A$, and 16 and 4 in line $R$. The maximum and minimum values of the number of live young rabbits were 16 and 3 in line $V, 13$ and 2 in line $A$, and 15 and 2 in line $R$. The maximum individual weight (99 g) was observed in the lower total number of young rabbits of 3 lines, while the minimum individual weight observed was $20 \mathrm{~g}$, in lines $A$ and $V$, and $22 \mathrm{~g}$, in line $R$. The postnatal survival of these young rabbits is very low. Unpublished data, taken in the same experimental period, indicated that $68 / 74(92 \%)$ of live young rabbits weighing less than $35 \mathrm{~g}$ at birth die during the $1 \mathrm{st}$ postnatal week.

The number of total and live young rabbits at birth were affected by line $(P<0.001)$. The line $V$ showed better results than line $A$ and $R$ (11.4 and 10.9 vs 9.2 and 8.8 for line $A$ and 10.2 and 9.0 for line $R, P<0.05$; table 1). However, while the differences between line $V$ and $A$ for live young rabbits were due to the different number of total born rabbits (least square mean [lsm] \pm SE: $9.8 \pm 0.2$ and $9.9 \pm 0.2$, respectively), the differences in line $\mathrm{R}$ cannot be explained by the different number of total born (Ism \pm SE: $9.2 \pm 0.2$ ). Line R showed a higher mortality at birth; however, the number of live young rabbits was also affected by parity $(P<0.05)$. Parities from 3rd to 9th had a favorable effect on the number of live young at birth. The differences were due to different losses at birth (Ism \pm SE: $9.9 \pm 0.1$ and $9.4 \pm 0.1$ ).

Only the linear coefficient between total and live young rabbits was significant $(0.94$, $P<0.001$; table II). When this relationship was analyzed separately for each line, only the quadratic coefficient was significant in line $A$ (linear: $0.86 \pm 0.02$ and quadratic: $-0.04 \pm 0.01, P<0.001 ; 0.96 \pm 0.05$ and $0.001 \pm 0.009$ for line $V$; and $0.97 \pm 0.06$ and $0.01 \pm 0.02$ for line $R$ ). Figure 1 shows the curve-linear relationship between the number of total and live young rabbits of line $A$.

The effect of line was not significant on litter weight, while the parity affected significatively the litter weight $(P<0.05)$; the 
Table I. Neonatal performances among lines and parities: number of total and live young rabbits (TYR and LYR), litter weight (LW) and individual weight (IW) at birth.

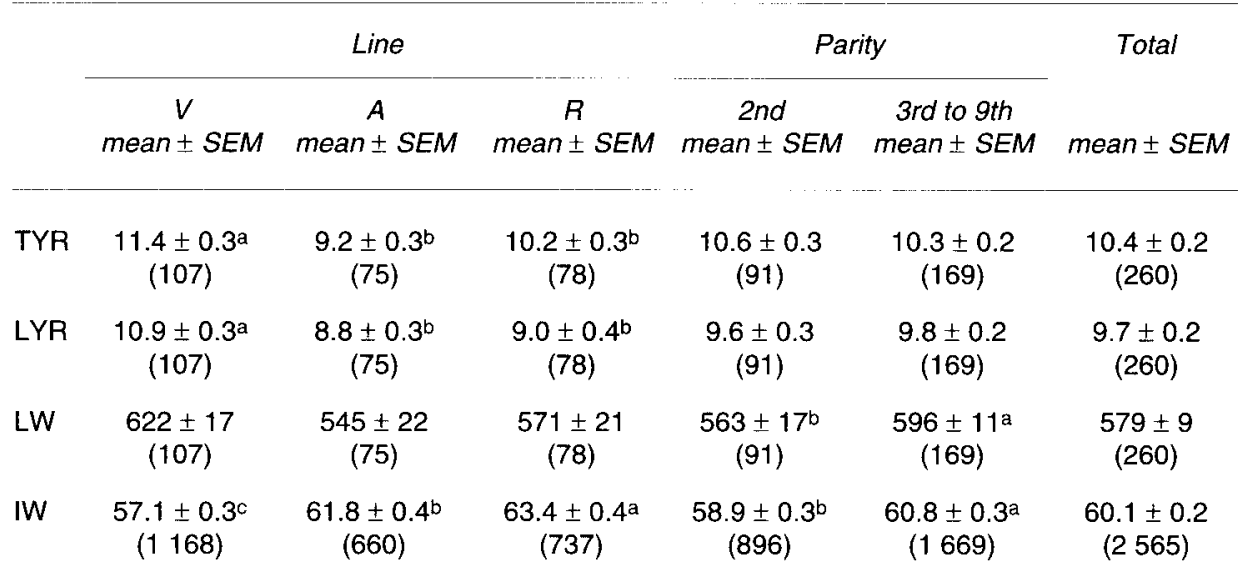

() number of data; mean \pm SE: mean \pm standard error of mean; $a, b, c$ : values within a row with different superscripts differ significantly $(P<0.05)$.

does with 3 or more parturitions had a positive effect on litter weight (596 vs 563, $P<0.05$; table I, Ism \pm SE: $602 \pm 8$ vs $555 \pm$ 11). In this case, both regression coefficients were significant (linear: 37.7 and quadratic:

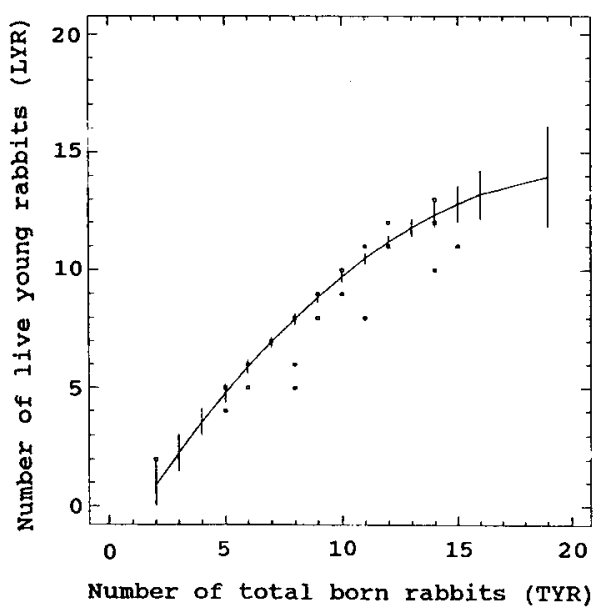

Fig 1. Relationship between the number of live young rabbits (LYR) and the total number of born rabbits (TYR) for line A with $95 \%$ intervals for means. Each point can represent several births.
-1.23 ; table II). Figure 2 shows the curve-linear relationship between litter weight and total number of young rabbits.

In the mixed model used to analyze the individual weight, aleatory common litter

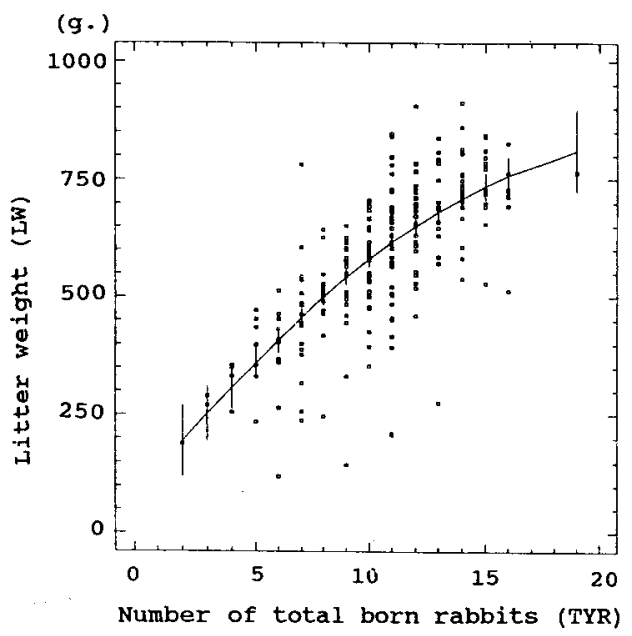

Fig 2. Relationship between the litter weight (LW) and the total number of born rabbits (TYR) for line A with $95 \%$ intervals for means. Each point can represent several births. 
Table Il. Effects of line (V, A, R) and parity (S: 2nd and T: 3rd to 9th). Regression coefficients of the total number of young rabbits at birth on number of live young rabbits (LYR), litter weight (LW) and individual weight (IW) at birth.

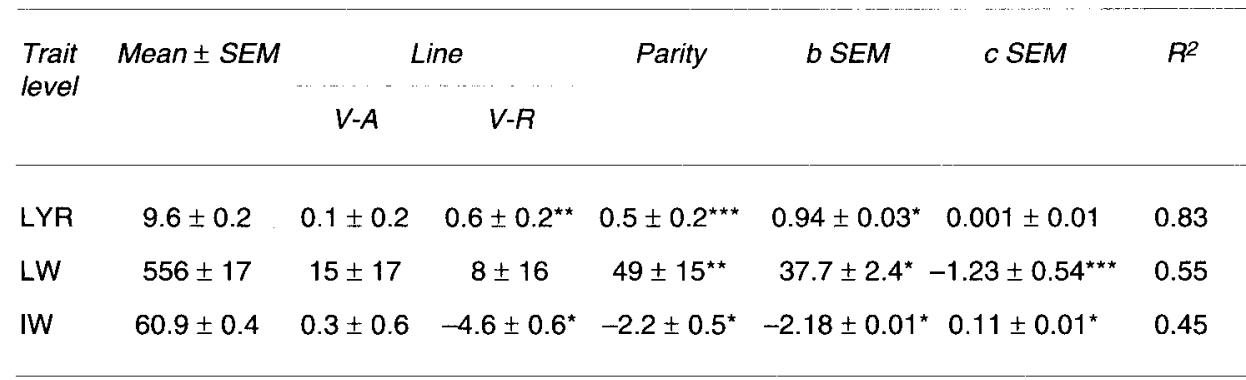

b: linear coefficient; c: curve-linear coefficient; mean \pm SE: mean \pm standard error.

${ }^{*} P<0.001 ;{ }^{* *} P<0.01,{ }^{* * *} P<0.05$.

effect was $27.31 \%$ of the total variance. The fixed effects, line and parity, were statistically significant $(P<0.001)$. Line $\mathrm{R}$, selected for growth, showed an individual weight higher than either line A or V $(63.4 \mathrm{~g}$ vs 61.8 $\mathrm{g}$ and $57.1 \mathrm{~g}$, respectively, $P<0.05$; table I). The 3rd to 9th parities had a positive effect on individual weight $(60.8 \mathrm{~g}$ vs $58.9 \mathrm{~g}$,

\section{(g.)}

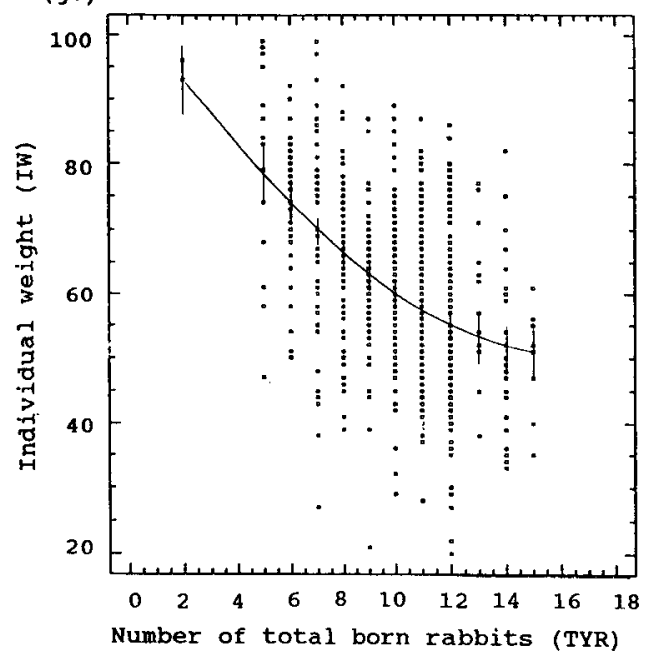

Fig 3. Relationship between the individual weight (IW) and the total number of born rabbits (TYR) for line A with $95 \%$ intervals for means. Each point can represent several births.
$P<0.05$, table I). The linear and curve-linear coefficients were significant $(-2.18$ and $0.11, P<0.001$; table II). When the model was fitted for each line, linear and curvelinear coefficients were significant in the 3 lines (linear: $-2.28 \pm 0.10,-2.57 \pm 0.11$, $-1.76 \pm 0.10$, and curve-linear: $0.12 \pm 0.01$, $0.19 \pm 0.01,0.09 \pm 0.01$ for lines $V, A, R$,

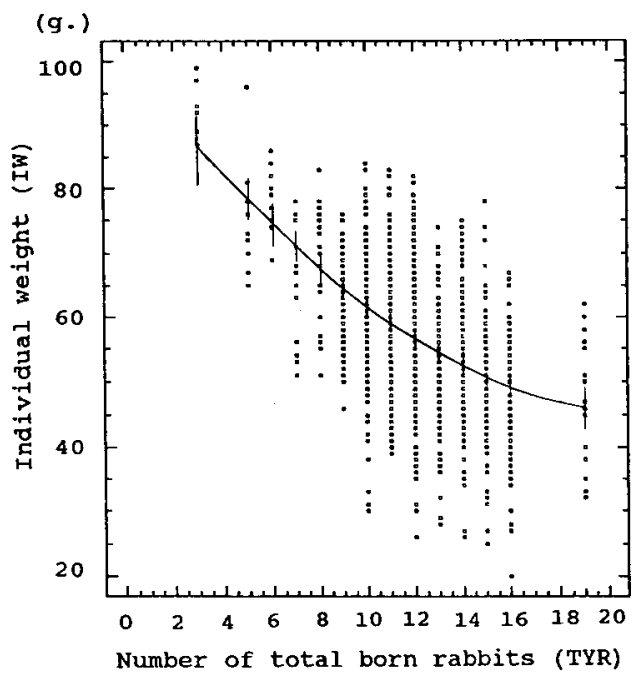

Fig 4. Relationship between the individual weight (IW) and the total number of born rabbits (TYR) for line $V$ with $95 \%$ intervals for means. Each point can represent several births. 
respectively). Figures 3,4 and 5 show the curve-linear relationship between individual weight and total number of young rabbits at birth in lines $A, V$ and $R$, respectively. The lines selected for litter size at weaning ( $A$ and $V$ ) show a better curve-linear relationship than line $\mathrm{R}$ (selected for growth).

\section{DISCUSSION}

The curve-linear relationship between the total number of young rabbits and live young rabbits and litter weight express reproductive limitations at parturition in does that support a higher number of foetuses to term. The existence of such a limit suggests that a possible increase in the number of live young rabbits could provoke an additional reduction of individual young weight. During the gestation when the number of implantations is high, a physical spacing restriction in the uterine horns could reduce the weight of foetuses carried to term and increase the mortality at the end of gestation, at birth and in the 1st days of postnatal life.

$$
\text { (g.) }
$$

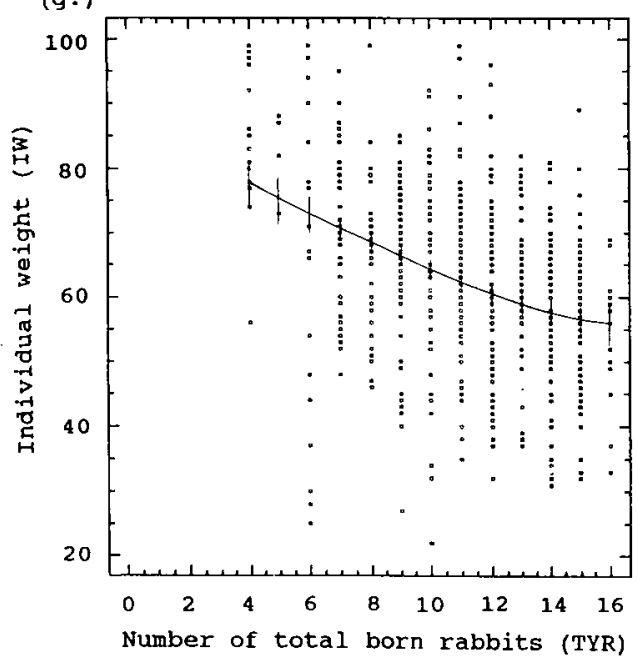

Fig 5. Relationship between the individual weight (IW) and the total number of born rabbits (TYR) for line $R$ with $95 \%$ intervals for means. Each point can represent several births.
Only line A showed limitations in both reprodutive traits.

Line A did not show these limitations 10 generations ago (García-Ximénez and Vicente, 1991). The litter size and litter weight were 7 and $331 \mathrm{~g}$, respectively (data from 228 births). Some factors have contributed to increase the reproductive performance of this line (nutrition, environment, genetics) and to modify the studied relationship. Line $V$ was also studied in this work. Then, the relationship between the total number of young rabbits and litter weight were not curve-linear as in the present study. Further control of this relationship could be interesting in subsequent generations.

It is well known that the birth weights of individual rabbits in large litters are less than those in small litters. This negative relationship between the number and the weight of the foetuses has been observed in most multiparous species (Salmon-Legagneur, 1968 ). This negative relationship was observed in 3 studied lines. However, line R, selected for growth rate, had regression coefficients lower than lines $A$ and $V$, selected for litter size at weaning. It is possible that the selection program produced this effect. The signifcance of quadratic coefficient could not be relevant, because it is necessary to obtain more data for large litters and to slaughter of pregnant does at the end of gestation to evaluate all living foetuses.

In rabbit does, the existence of limits on the minimum number of foetuses required for the maintenance of gestation to term and on the size of foetuses at birth has also been observed (Adams, 1962). In this study, the 3 lines showed the same maximum individual weight of young rabbits at birth $(99 \mathrm{~g})$, and identical minimum individual weight of live young rabbits $(20-22 \mathrm{~g})$. This minimum weight was also observed in hemiovariectomized rabbits does from line V (GarciaXiménez and Vicente, 1993). This weight 
could be near a limit value that is related to the minimum individual weight compatible with survival at birth. However, we observed a high mortality of pups born at a weight of less than $35 \mathrm{~g}$. The differences observed between the lowest and the highest minimum individual weight of live pups indicates the adaptability of foetal growth.

This study suggests that line A, selected for litter size at weaning, could be nearer to their reproductive limits at birth than either the $V$ or $R$ line, since this line expresses curve-linear relationships for the 3 reproductive traits.

\section{ACKNOWLEDGMENTS}

We wish to thank Drs M Baselga and E Gómez for statistical assistance.

\section{REFERENCES}

Adams CE (1962) Studies on prenatal mortality in the rabbit, oryctolagus cuniculus: the effect of transferring varying numbers of eggs. $J$ Endocrinol 24,471 490

Breuer HW, Claussen V (1977) Correlation of birth weight and crown-rump to the number of implantations and litter size in rabbits. Anat Embryol 151, 91-95

Duncan SLB (1969) The partition of uterine blood in the pregnant rabbit. J Physiol 204, 421-433

Estany J, Baselga J, Blasco A, Camacho J (1988) Mixed model methodology for the estimation of genetic response to selection in litter size of rabbits. Livest Prod Sci 21, 67-75

Garcia-Ximénez F, Vicente JS (1991) Propuesta de un criterio de valoración de la capacidad uterina númerica en coneja. ITEA 87(1), 65-71

Garcia-Ximénez F, Vicente JS (1993) Limiting effects of uterine crowding on the number and weight of live pups at birth in hemiovariectomized and normal rabbit does. Reprod Nutr Dev 33, 69-73

Gluckman PD (1986) The regulation of fetal growth. In: Control and manipulation of animal growth (PJ Buttery, DB Lindsay, NB Haynes, eds), Butterworths, London, UK, 85-104

Holland MD, Odde KG (1992) Factors affecting calf birth weight: a review. Theriogenology 38, 769-798

Korda P, Dembrosky J (1968) Effect of the interval between successive pregnancies on pregnancy duration and litter size in rabbits. Zwierzeta Laboratoryine 6, 37-42

Meyer K (1988) DFREML, a set of programs to estimate variance components under an individual animal model. J Dairy Sci 71 (Suppl 2), 33-34

Salmon-Legagneur $E$ (1968) Prenatal development in the pig and some other multiparous animals. in: Growth and development of mammals (GA Lodge, GE Lamming, eds), Butterworths, London, UK, 158-191

SAS (1989) Statistical Analysis System, copyright 1989 , SAS institute, Inc, Cary, NC, USA

Torres C, Plá M, Garciá-Ximénez F (1986) Factores que inciden sobre los componentes de la camada a parto. XI Symposium Nacional de Cunicultura, Teruel, Spain, 97-104

Widdowson EM (1976) Environmental control of growth: the maternal environment. In: Meat animals, growth and productivity (D Lister, DN Rhodes, VR Fowler, MF Fuller, eds), Plenum Press, New York, 273-284

Wilmut I, Haley CS, Simons JP, Webb R (1990) Prospects for application of molecular genetic manipulation to improve reproduction. Proceedings of the Fourth World Congress on Genetic Applied to Livestock Production, Edinburgh, vol 16, 281-291 